\title{
Daydream Archive
}

\author{
Felicity Callard
}

\begin{abstract}
Felicity Callard's interest in the long history of research into daydreaming, fantasy and reverie, and the ways in which this subterranean tradition might productively complicate contemporary cognitive scientific investigations of mind wandering, has been a significant focus of her work for Hubbub. In this chapter, she conjures up an imaginary archive of the daydream, as yet dispersed across disciplinary fields and points in time and space, alludes to some of its heterogeneous contents, and asks what the power of such an archive-to-come might be.
\end{abstract}

Keywords Digression - Fantasy · History of psychology - History of the human sciences $\cdot$ Mind wandering

'People would rather be electrically shocked than left alone with their thoughts.' Such was the title that Science used to report on a study in which college students, left in a room with only their own company, seemed to prefer 'doing mundane external activities' and even to 'administer electric shocks to themselves' rather than be left with their own thoughts. The

F. Callard $(\bowtie)$

Durham University, Durham, United Kingdom

e-mail: felicity.callard@durham.ac.uk

(C) The Author(s) 2016

F. Callard et al. (eds.), The Restless Compendium, DOI 10.1007/978-3-319-45264-7_5 
researchers ended their article with the strong - and disputable - claim: 'The untutored mind does not like to be alone with itself'. 'Their study is one of many recent scientific contributions to a bulky and heterogeneous body of work (which extends across many centuries, ${ }^{1}$ and involves many kinds of practitioners) that both investigates and makes strong interpretations about the shape, qualities and content of humans' inner worlds when they are not predominantly attending to the world outside. The terms used are many: daydreaming, mind wandering, fantasy, wool-gathering, stimulus independent thought, reverie. The extent to which they could be said to describe the same phenomenon is open to debate, and indeed to historically nuanced contestation. The complexity and opacity of such experiences - how difficult they are to relate to ourselves let alone to others, how closely they seem bound to our very experience of being human - seems not to dent the desire of many both to generalize and to make judgments about them. (Another recent exemplar is the psychological study titled 'A wandering mind is an unhappy mind'.) ${ }^{2}$

I am interested in how investigations and interpretations of daydreaming and associated states (mind wandering, fantasy and so on) variously construe particular kinds of inner experience as estimable, pathological, normative, dangerous or constitutive of particular kinds of subjectivity. They reveal a great deal about the assumptions we all make, whether we are scientists or not, about the wandering mind - its ability to open up and fold away the self; the strange temporal and spatial logics that are constituted through its wandering; its capacities both to shield its owner from, as well as render her vulnerable to, the world beyond her head; its ability both to separate itself from, and yoke itself to, the peregrinations of the body; and its potential to enjoin other minds to trace new political and social worlds. Various accounts of the daydream, or of the wandering mind, open different possibilities for understanding how the world gets inside us, and for how our inner life can feel, at times, as though it colonizes the world. When does the daydream tip into the hallucination? How has its border with the night dream experienced its own conceptual wandering, across different times and in different locations? And which kinds of settings and environments have been privileged in deliberate attempts to elicit - whether in others, or in ourselves - the daydream? For it is not only when physically alone that we can be alone with our thoughts. How, then, does the daydream take up habitation when its host is in the

\footnotetext{
${ }^{i}$ See Chaps. 3 and 4.
} 
company of others - and what are the methods that others have used in attempting to spot that move? ${ }^{3}$

If Jerome Singer, one of the architects of twentieth-century scientific research on these topics, is correct to describe daydreaming as 'so elusive a phenomenon', ${ }^{4}$ that does not gainsay the fact that the daydream, in and perhaps because of - its very elusiveness, calls for its own archive. The historian of science Rebecca Lemov writes of the efforts, at times overweening, that were made by human scientists after the Second World War to record the dreams, stories and intimate thoughts of a vast number of people across the world (many of them colonial subjects). She exposes a powerful desire on the part of these researchers to 'collect traces of subjectivity itself, to make an archive of the inner contents of the mind'. ${ }^{5}$ Those human scientists are not alone in their efforts to pinion and to anatomize the shifting shapes of the moving mind.

From what, then, might the archive of the daydream be built? It would contain carefully planned attempts to elicit, capture, represent and store the daydream. It would contain the ghosts of different kinds of experimental apparatus, used in different kinds of settings. It would include the graphical marks of creative writers, traces of scientists engaging in reverie as part of their experimental procedures ${ }^{6}$ and photographs of research psychologists' laboratories. It would contain the scales and measures that have been developed in the hope that their mesh would help disaggregate the elements of the daydream. ${ }^{7}$ It would include case histories documenting daydreams that were unravelled in psychoanalytic consulting rooms. It would build on archival repositories that have attempted systematically to preserve the fugacious alongside the durable. ${ }^{8}$ But it would also contain records of daydreams that have erupted even when not actively sought out or elicited: the many school records that have lamented a pupil's tendency to be lured away into a fantasmatic world beyond the classroom, alongside recent case reports in clinical literatures that mark the emergence of the new category: 'excessive' or 'maladaptive' daydreaming.'

This archive would also be constituted from writings that harness daydreaming and mind wandering to make adjudications about different kinds of people. ' $[\mathrm{R}]$ everie is the automatic mental action of the poet', wrote nineteenth-century physiologist William Carpenter: the poet, unlike the 'reasoner' with his [sic] commitment to abstraction, 'give[s] the reins to his Imagination, whilst gazing fixedly upon some picturesque cloud, or upon the every-varying surface of a pebbly brook' - leaving his 
'thoughts and feelings' to wander 'hither and thither'. ${ }^{10}$ Carpenter is one of many in his efforts to install distinctions between human 'types' by dint of their resort to daydreaming, or for their tendency to daydream in different ways and about different kinds of things. A proclivity to daydream has, for example, on a number of occasions in the twentieth century been tightly tied to adolescence, as well as regarded as early evidence of psychosis in children. ${ }^{11}$ It has been, and remains till today, a common mark of psychopathology. This putative archive would also take an interest in who has held, at different historical moments, the authority and the power to elicit, collect and anatomize the tangled workings of others' mental wanderings. We might also consider how that archive would grow if we started from the position that the daydream is constituted through and as a collectivity rather than hiding in the depths of one lone mind. ${ }^{12}$

\section{Rummaging Through the Archive}

I am in the midst of rummaging through fragments that I believe would belong to the archive of the daydream. I am focusing on experimental investigations that took place across what we could call the long twentieth century. These stretch from the heterogeneous efforts made by psychologists, psychoanalysts, psychiatrists and neurologists in the finde-siècle to delineate and track fantasies, reverie and daydreams, up to the recent efflorescence of cognitive neuroscientific research on mind wandering, which has accompanied the rise of resting-state functional magnetic resonance imaging (fMRI) research and the focus on the brain's default mode network. ${ }^{\text {ii }}$ Research on wandering and daydreaming has, after several decades of being marginalized in psychological research, come in from the cold. The terrain of the daydream has today been claimed, in terms of scientific approaches, by cognitive psychological models. (These include the hypothesis of the decoupling of attention and perception so as to allow the brain efficiently and adaptively to process streams of external and internal information. $)^{13}$ The number of publications and experiments on mind wandering within cognitive neuroscience today implies that the dispersed archive of the daydream is growing prodigiously.

In rummaging through older parts of this would-be archive - in tracing the subterranean histories and geographies of the daydream - I

\footnotetext{
ii See Chap. 2.
} 
wish not only to contribute to the historical geography of the human sciences. I want, too, to think through how such histories might be used to put pressure on today's psychological models of mind wandering. There is, I believe, the possibility of cross-pollinating, or even infecting, current scientific models with older accounts of the daydream, fantasy or reverie. The daydream archive holds multiple maps for how to navigate the putting together of bodies, minds and settings: rather than being read as historical artefacts, those maps might have utility for mind wandering wayfarers today.

If I have called my method one of rummaging, it is also one of daydreaming. I am moving across different disciplinary terrains, and encountering along the way different practices and methods of observation and elicitation for capturing the daydream, the fantasy and the travels of the wandering mind. This I experience, often, as a barely structured journey, one that feels its way and is alive to the pleasures of digression. .ii $^{\text {Tii }}$ Those different practices and experiments throw up models of the mind, and of the external and internal world, that are often incommensurable with one another. But, like the images and elements of a daydream, they can sit, somehow, cheek by jowl, rather than push one another out.

Such divagation through the archive of the daydream, then, might serve to throw up other ways of narrating the history of today's scientific field of mind wandering research - as well as displace some of the preoccupations of the present. Today's mind wandering models have emerged in the shadow of cognitive psychological task-based analyses. And these bring with them the frequent desire for clear distinctions that can be operationalized within experimental paradigms (e.g. 'externally focused' and 'internally focused'; focused on 'self' or 'other'; thinking of 'past' or 'future'). . But the work of the daydream is work that unties such distinctions. This would-be daydream archive, then, holds the traces of bodies, minds and instruments that have not adhered to clean partitions. It holds multiple elaborations of how a mind might like to be alone with itself.

Acknowledgements This work was supported both by the Wellcome Trust $[103817 / \mathrm{Z} / 14 / \mathrm{Z}]$ and the Volkswagen Foundation.

iii See Chap. 13.

iv See Chap. 6. 


\section{Notes}

1. Timothy D. Wilson et al., 'Just Think: The Challenges of the Disengaged Mind', Science 345, no. 6192 (2014): 75-77.

2. Matthew A. Killingsworth and Daniel T. Gilbert, 'A Wandering Mind Is an Unhappy Mind', Science 330, no. 6006 (2010): 932.

3 . Changes in ocular motility, for example, have been used as a potential proxy for a shift into a daydreaming state; see Bonnie B. Meskin and Jerome L. Singer, 'Daydreaming, Reflective Thought, and Laterality of Eye Movements', Journal of Personality and Social Psychology 30, no. 1 (1974): 64-71.

4. Jerome L. Singer, Daydreaming and Fantasy (London: Allen and Unwin, 1976), 5 .

5. Rebecca Lemov, 'Towards a Data Base of Dreams: Assembling an Archive of Elusive Materials, c. 1947-61', History Workshop Journal67, no. 1 (2009), 46.

6. Tiffany Watt-Smith, 'Henry Head and the Theatre of Reverie', 19: Interdisciplinary Studies in the Long Nineteenth Century 12 (2011). doi: http://doi.org/10.16995/ntn.595.

7. For example, the Imaginal Processes Inventory discussed in Jerome L. Singer and John S. Antrobus, 'A Factor-Analytic Study of Daydreaming and Conceptually-Related Cognitive and Personality Variables', Perceptual and Motor Skills 17, no. 1 (1963): 187-209.

8. In addition to the database described by Rebecca Lemov (see her Database of Dreams: The Lost Quest to Catalog Humanity [New Haven, N.J.: Yale University Press, 2015]), see also projects such as the Mass Observation Archive.

9. Cynthia Schupak and Jesse Rosenthal, 'Excessive Daydreaming: A Case History and Discussion of Mind Wandering and High Fantasy Proneness', Consciousness and Cognition 18, no. 1 (2009): 290-92.

10. William Benjamin Carpenter, Principles of Mental Physiology: With Their Applications to the Training and Discipline of the Mind, and the Study of Its Morbid Conditions, 6th ed. (London: Kegan Paul, Trench \& Co., 1888), $544,545$.

11. Stanley Hall, in his monograph on adolescence, argued that 'inner absorption and reverie is one marked characteristic of this age of transition' (Adolescence: Its Psychology and Its Relations to Physiology, Anthropology, Sociology, Sex, Crime, Religion and Education. (New York, N.J.: Appleton, 1904); see also Charles Bradley, 'Early Evidence of Psychoses in Children', Journal of Pediatrics 30, no. 5 (1947): 529-40.

12. Ernst Bloch, The Principle of Hope, trans. Neville Plaice, Stephen Plaice, and Paul Knight, Vol. 1 (Cambridge, Mass.: MIT Press, 1995).

13. Jonathan Smallwood and Jonathan W. Schooler, 'The Science of Mind Wandering: Empirically Navigating the Stream of Consciousness', Annual Review of Psychology 66 (2015): 487-518. 


\section{Further Reading}

Crary, Jonathan. Suspensions of Perception: Attention, Spectacle, and Modern Culture. Cambridge, Mass.: MIT Press, 1999.

Lofgren, Orvar, and Ehn, Billy. The Secret World of Doing Nothing. Berkeley, Calif.: University of California Press, 2010.

Felicity Callard is Director of Hubbub and an academic at Durham University (Department of Geography and Centre for Medical Humanities). Her interdisciplinary research focuses on the history and present of psychiatry, psychology, psychoanalysis and the neurosciences. She is co-author of Rethinking Interdisciplinarity across the Social Sciences and Neurosciences (Palgrave Macmillan, 2015).

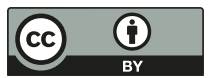

This chapter is distributed under the terms of the Creative Commons Attribution 4.0 International License (http://creativecommons.org/ licenses/by/4.0/), which permits use, duplication, adaptation, distribution and reproduction in any medium or format, as long as you give appropriate credit to the original author(s) and the source, a link is provided to the Creative Commons license and any changes made are indicated.

The images or other third party material in this chapter are included in the work's Creative Commons license, unless indicated otherwise in the credit line; if such material is not included in the work's Creative Commons license and the respective action is not permitted by statutory regulation, users will need to obtain permission from the license holder to duplicate, adapt or reproduce the material. 